idea as a reductio ad absurdum of the whole subject, but for those who enjoy a speculative romp across some of the most fascinating topics in modern physics, Gott's book will prove a delightful challenge.

Paul Davies is visiting professor of physics at Imperial College, London SW7 2AZ, UK, and author of How to Build a Time Machine (Penguin), to be published later this year.

\section{Cut-and-paste knowledge}

\section{Encyclopaedic Visions: Scientific \\ Dictionaries and \\ Enlightenment Culture}

by Richard Yeo

Cambridge University Press: 2001. 358 pp. $\mathfrak{E} 40, \$ 59.95$

\section{W. F. Bynum}

One of my son's babysitters was an elderly woman who also looked after children of other Cambridge research students. When she closed her cottage to move in with her own son, she rewarded all her bookish friends with a remembrance: each received a single volume from her set of the Everyman Encyclopaedia. I never knew if the fact that I got the first volume was a particular sign of affection, or something rather more random.

Odd volumes of encyclopaedias may contain a lot of useful information, but they are best in complete sets. 'Twas ever thus, as Encyclopaedic Visions, Richard Yeo's sensitive and engaging study of Enlightenment encyclopaedias, makes clear. After all, the cycle embedded in the word 'encyclopaedia' carries with it the implication that all human knowledge is connected in some organic way. Most medieval and early modern works within the genre carried a statement or diagram, or both, attesting to such unity.

In spite of this rich historical tradition, modern encyclopaedias emerged only during the Enlightenment. At first glance, the Enlightenment reference book might be thought to be the Encyclopédie of Denis Diderot and Jean D'Alembert. Much has been written about the creation, publishing history and influence of this monumental work, whose aggressively secular nature brought both of its editors (and some of its contributors) into confrontation with the authorities in ancien régime France.

As Yeo reminds us, however, the Encyclopédie began its life as a planned translation of a work produced single-handedly by an English hack, Ephraim Chambers. So successful was Chambers' Cyclopaedia, first published in two volumes in 1728, that it turned its obscure author into a successful man of letters and earned him election to the Fellowship of the Royal Society (the eighteenth-

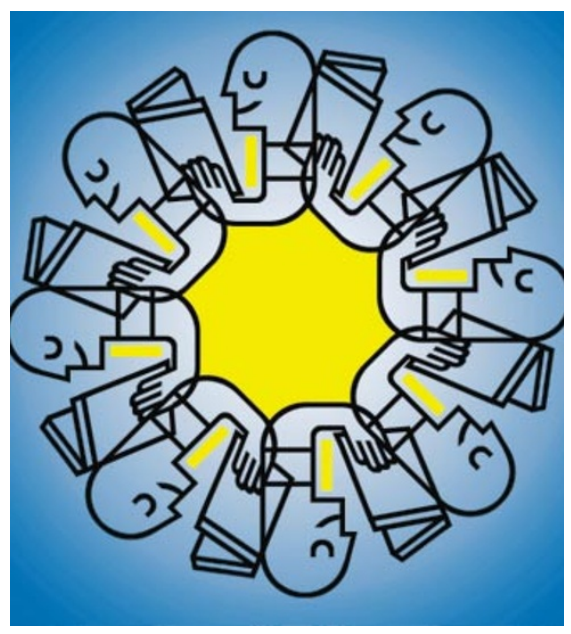

century Royal Society was happy enough to elect science popularizers to its midst).

Chambers' Cyclopaedia is central to Yeo's analysis, and science was at the heart of Chambers' work, as well as that of his successors and imitators. The objectivity of scientific knowledge gave it a special place in Enlightenment culture, raising it above the divisiveness of politics or religion. Science was thus fundamental to the ethos of selfimprovement that featured in the rhetoric with which encyclopaedias were announced, advertised and justified. The scientific and technical contributions of Chambers, John Harris, Abraham Rees and the other encyclopaedists of the period were often highly original and much remarked upon.

But if the encyclopaedias were surrounded by an aura of utility and progress, they were, especially in Britain, products of commercialism and profit. In continental Europe, several learned societies undertook the systematic task of producing versions of the encyclopaedic ideal. Most of these projects either foundered or took decades to be realized. The British seemed to vacillate between pride at their own individual enterprise and initiative and envy of the more systematic way in which learned activity was organized on the Continent. Thus, the first edition of the Encyclopaedia Britannica (three volumes, 1768-71) was written single-handedly by the Edinburgh printer William Smellie (by his own admission with a paste-pot and a pair of scissors). Its title page, however, announced that it had been produced by "A Society of Gentlemen".

Smellie's mode of composition was hardly surprising: no one, even in the Athens of the North, could be expert in all branches of human knowledge. The key to producing a good encyclopaedia was knowing which authorities to summarize. This raised the tricky issue of copyright, even at a time when the legal protection of intellectual property was weak and pirated editions were regularly produced. The first edition of the Encyclopaedia Britannia actually produced a lawsuit, partly because of Smellie's liberal use of the scissors and paste-pot, but mostly because London publishers and booksellers were nervous that this new encyclopaedia on the block originated in Scotland.

The Encyclopaedia Britannica not only survived these early rumblings, it actually thrived, and by the time of its third edition (1788-97) it had swelled to 18 volumes and acquired many of the trappings of modernity. Although still responsive to market forces, this $E B$ was the work of identified experts. Although it aimed at comprehensive coverage of all branches of human knowledge, its scientific content was still central, science being recognized as the most active and rapidly changing field of knowledge, and therefore the one that dictated the necessity for frequent updating.

Yeo's monograph is solidly historical, but it reminds us that many of the issues of encyclopaedic form and content grappled with during the Enlightenment are still with us. Should encyclopaedias be principally repositories of authoritative knowledge where the learned can refresh their knowledge, or instruments to educate the novice? If science is about the objective understanding of nature, should it be subject to copyright? These and many other themes that Yeo scrutinizes are still current in our age of electronic publishing and the Human Genome Project.

W. F. Bynum is at the Wellcome Trust Centre for the History of Medicine, University College London, 24 Eversholt Street, London NW1 1AD, UK.

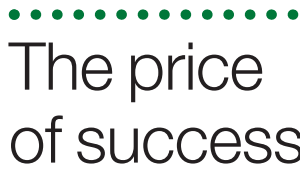

\section{Science, Money, and Politics: \\ Political Triumph and \\ Ethical Erosion \\ by Daniel S. Greenberg \\ University of Chicago Press: 2001. 528 pp.

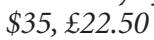

\section{David Dickson}

Two characteristics instantly strike any observer of the scientific enterprise in the United States. The first is its vitality and productiveness. The second is a level of financial support that, even in difficult economic times, has remained the envy of virtually all other industrialized nations.

A third characteristic, perhaps less immediately obvious but no less striking, is the longevity of its support structures. In other countries, research councils and funding agencies find their names and responsibilities altered as politicians seek to modify their roles in the face of changed economic circumstances. In contrast, the organizational landscape of US science has remained virtually unchanged for the past half-century.

For anyone interested in understanding 
at least the second two of these characteristics, Daniel Greenberg's book, the product of almost four decades of close observation of the Washington science scene by one of its most acute analysts and sharpest critics, is essential reading.

Greenberg, a former news editor of Science, for many years chronicled in his fortnightly newsletter, Science and Government Report, the complex interaction between the scientific community and the political establishment. No one, therefore, is better placed to document how each has successfully managed to meet the needs of the other since the end of the Second World War.

Greenberg does not deny that this symbiotic relationship must take much of the credit for the current strength of US science and its dominance of the world stage. But he argues that there has been a heavy price to pay in terms of the intellectual and ethical cost of getting there.

For example, one consequence of the successful pursuit of self-interest by the scientific community - the "political triumph" referred to in the book's title — has been an innate conservatism that Greenberg claims has, ironically, led to its increasing estrangement from mainstream politics.

A second consequence, he argues, has been a lowering in the intellectual integrity of the political discourse around science. Greenberg points out, for example, that many still invoke the name of Vannevar Bush to justify the protection of basic research funding from direct political interference. But few of these, he claims, are aware of the extent to which Bush's ideas were modified — and some of them rejected — during the process of setting up the system for funding science after the Second World War with which his name is identified.

At the same time, Greenberg argues, scientists have become increasingly disinclined to take up the moral causes that fired a previous generation of scientific leaders to campaign against issues such as nuclearweapons testing or environmental degradation. He describes the main preoccupation of today's scientist, outside his or her scientific work, as "grubbing for money", and laments that "the demobilisation of science from politics and social engagement is a fact of scientific life".

Greenberg is at his best when tracking in painstaking detail, often using internal documents obtained in the course of preparing material for his newsletter, the way in which dubious lines of argument can take on a virtually unquestioned life of their own if they are found suitable for building a case for greater science funding.

Such, for example, was the case when the National Science Foundation set out in the mid-1980s to argue the case, based on a remarkable lack of hard data, that the United

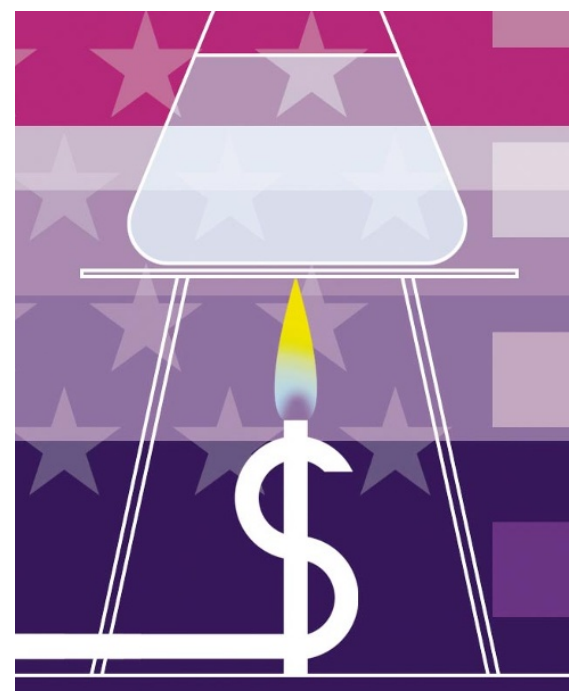

States faced a damaging shortfall in the production of scientists and engineers. The argument was dropped in the early 1990s when it became clear that this was unlikely to occur.

He is also adept at undermining some of the myths about the degree of influence that scientists have over political affairs outside their direct spheres of activity. Their impotence is reflected, for example, in Greenberg's documentation of the continuous failure of the scientific community - or the "scientific enterprise", as he calls it - to establish a strong scientific presence in the Department of State. As a result, he writes, the department "has persisted in a benighted indifference to things scientific, sometimes to the astonishment and dismay of scientists who cross its path".

Many scientists continue to believe that science's generous support from the federal government is based primarily on the innate value of its potential contribution to social well-being. Greenberg's analysis of such events may well cause them to reconsider their view of how decisions about science funding are taken in practice.

There are shortcomings in his analysis that will no doubt be eagerly leapt on by those reluctant to accept the relatively unflattering portrait of US science that Greenberg presents. One is that, for all its institutional conservatism and self-serving politicking, US science has been remarkably productive in the period he describes. As far as science itself is concerned, and whatever Greenberg says about its innate conservatism, it is difficult to see how different strategies could have led to even greater achievements.

Second, there are some significant gaps in the analysis. For example, Greenberg spends considerable time analysing the misguided hubris that accompanied the collapse of political support for the Superconducting Supercollider in the early 1990s — and the political factors that ensured the survival of a far less scientifically deserving project, the International Space Station.

But he pays scant attention to perhaps the greatest single science project of the past decade, namely the sequencing of the human genome. This receives merely a passing comment, being linked dismissively with various ill-fated experiments in gene therapy as a product of the joint pursuit of "scientific glory and biotech profit".

Finally, Greenberg's book does little to explain how his main remedy for the ills he describes - that scientists should "come out of the ghetto" and become more directly involved in conventional politics - are likely, on their own, to change things.

None of these shortcomings, however, detracts from the value of this book as a unique and revealing perspective on the way that the science-funding process actually works in Washington. The picture it paints is not a flattering one. But - unlike many of those he writes about — Greenberg is not out to make friends in high places.

David Dickson, a former news editor of Nature, is at SciDev.Net, 11 Rathbone Place, London W1T 1HR, UK.

\section{An astronomical adventure story}

\section{Beyond Pluto: Exploring the Outer Limits of the Solar System}

by John Davies

Cambridge University Press: 2001. 244 pp.

$\mathfrak{1 7}$ 17.95, \$24.95

\section{Joel Wm. Parker}

The fact that our Solar System consists of more than just nine planets and an asteroid belt between Mars and Jupiter is still sinking into the public psyche. But among Solar System researchers, the importance of the Kuiper belt beyond Neptune has been known for quite a while. This region contains another 'asteroid belt', which is the source of comets and will provide a glimpse into both the chemical and the dynamic infancy of the Solar System.

Considering the recent public debate over the planethood of Pluto, and the onagain, off-again politics of NASA's Pluto-Kuiper Express mission, now is a particularly opportune time to publish Beyond Pluto. John Davies' book on the history and scientific relevance of these denizens of the outer Solar System is aimed at the general reader as well as the astronomer.

The history of the Kuiper belt is both old and recent. As early as the 1930s, after Pluto was discovered, there was speculation about the possible existence of a population of small bodies in the outer Solar System of which Pluto was just the tip of the iceberg. Kenneth 